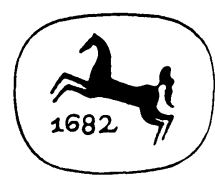

Sammlung Metzler Band 185 
Roger Paulin

\section{Ludwig Tieck}

\section{J. B. Metzlersche Verlagsbuchhandlung Stuttgart}


CIP-Kurztitelaufnahme der Deutschen Bibliothek

Paulin, Roger:

Ludwig Tieck/Roger Paulin.

- Stuttgart: Metzler, 1987

(Sammlung Metzler; M 185)

ISBN 978-3-476-10185-3

NE: GT

ISSN 0558-3667

ISBN 978-3-476-10185-3

ISBN 978-3-476-03891-3 (eBook)

DOI 10.1007/978-3-476-03891-3

M 185

(C) 1987 Springer-Verlag GmbH Deutschland

Ursprünglich erschienen bei J. B. Metzlersche Verlagsbuchhandlung und Carl Ernst Poeschel Verlag GmbH in Stuttgart 1987 


\section{Inhalt}

Abkürzungen ....................... VI

Einleitung: Zur Tieckforschung. ............ 1

Leben und Werk Ludwig Tiecks ............. 11

I. $1773-1799 \ldots \ldots \ldots \ldots$. . . . . . . . . . . . . . . . . . 11

(a) Jugend $\ldots \ldots \ldots \ldots \ldots \ldots \ldots \ldots \ldots \ldots \ldots \ldots \ldots \ldots$

(b) Studienzeit . . . . . . . . . . . . . . . . . 17

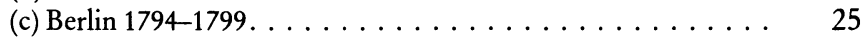

II. $1799-1819 \ldots \ldots \ldots \ldots \ldots \ldots \ldots \ldots$. . . . . . . . . . . . 50

(a) Wanderjahre $1799-1810 \ldots \ldots \ldots \ldots \ldots \ldots \ldots . \ldots \ldots$

(b) Tiecks Mittelalter-Studien . . . . . . . . . . . . . . 69

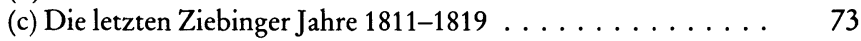

III. Dresden $1819-1841 \ldots \ldots \ldots \ldots \ldots$. . . . . . . . . . 80

IV. Tiecks Gelehrtentätigkeit und Essayistik . . . . . . . . 95

(a) Tieck und Shakespeare . . . . . . . . . . . . . 96

(b) Tieck und Ben Jonson . . . . . . . . . . . . . . . . . . 105

(c) Tiecks Herausgebertätigkeit . . . . . . . . . . . . . . 106

(d) Tieck und die bildenden Künste . . . . . . . . . . . 111

V. Die letzten Jahre: Berlin $1841-1853 \ldots \ldots \ldots \ldots \ldots \ldots .113$

VI. Zur Nachwirkung Tiecks . . . . . . . . . . . . . . . 117

Namenregister . . . . . . . . . . . . . . . . . . 120

Gesammelte Ausgaben von Tiecks Werken . . . . . . . . 128

Übersetzungen, Editionen, Vorworte für Werke anderer. . . 131 


\section{Abkürzungen}

BüSh

DLE

DVjs.

EG

GLL

GR

GRM

JDSG

JdShG

JEGP

JFDH

Köpke

KS

LWJB

MLQ

MLR

N.

NS

PMLA

rde

rub

Schriften

Schweikert

Segebrecht

SW

$\mathrm{ZfdPh}$
Das Buch über Shakespeare

Deutsche Literatur in Entwicklungsreihen

Deutsche Vierteljahrsschrift für Literatur-

wissenschaft und Geistesgeschichte

Etudes Germaniques

German Life and Letters

Germanic Review

Germanisch-Romanische Monatsschrift

Jahrbuch der deutschen Schiller-Gesellschaft

Jahrbuch der deutschen Shakespeare-

Gesellschaft

Journal of English and German Philology

Jahrbuch des Freien Deutschen Hochstifts

Rudolf Köpke: Ludwig Tieck, Leipzig 1855

Kritische Schriften

Literaturwissenschaftliches Jahrbuch

Modern Language Quarterly

Modern Language Review

Nachlaß

Nachgelassene Schriften

Publications of the Modern Language

Association of America

rowohlts deutsche enzyklopädie

Reclams Universal-Bibliothek

Ludwig Tieck's Schriften, Berlin 1828-54

Ludwig Tieck, München 1971, Dichter über ihre Dichtungen 9 I-III

Ludwig Tieck, Darmstadt 1976,

Wege der Forschung 386

August Wilhelm Schlegel's sämmtliche Werke, hg. v. E. Böcking, Leipzig 1846-48

Zeitschrift für deutsche Philologie 